\title{
MATRIMONIO IGUALITARIO. RECONSTRUCCIÓN Y POSICIÓN FRENTE A UNA CONTROVERSIA FILOSÓFICA, POLÍTICA Y JURÍDICA
}

Gay marriage. Reconstruction and position faced with a philosophical, political and judicial controversy.

\author{
MAUROBASAURE \\ Universidad Andrés Bello (Chile) \\ mauro.basaure@gmail.com
}

\section{Resumen}

Mediante la metodología de una reconstrucción inmanente del mejor argumento de quienes se oponen al reconocimiento jurídico del matrimonio entre personas del mismo sexo, este artículo muestra por qué el juez o el legislador no debe aceptar dicho argumento. Con ello se señala solo indirectamente o de modo negativo por qué sí debe ser reconocido dicho matrimonio. En este artículo se reconstruye la estructura y los diferentes contenidos de las justificaciones opositoras, buscando identificar la más robusta de ellas; esto es, aquella con mayor capacidad para-recurriendo a argumentos adecuados a sociedades plurales-traspasar el peso de la prueba al lado de la demanda por dicho reconocimiento. Dicha capacidad se comprueba mostrando concretamente cómo tal justificación logra argumentos de defensa, de crítica a dicha demanda, así como incorporar argumentos del mundo progresista. Pese a su robustez y luego de una evaluación detenida, se concluye que esa justificación no es sostenible bajo medios racionales.

Palabras claves: Matrimonio homosexual; sistema jurídico; justificación; reconocimiento; liberalismo.

\begin{abstract}
Through a methodology of an immanent reconstruction of the best argument of those who oppose the legal recognition of same-sex marriage, this article shows why the judge, or the legislator should not accept this argument. With this, it is pointed out indirectly and in a negative way why that marriage should be recognized. In this article the structure and the different contents of the conservative justifications are reconstructed, trying to identify the most robust of them; that is, the one with the highest capacity for-using adequate arguments to plural societies - to transfer the burden of proof to the side of the demand for such recognition. This capacity is demonstrated by showing precisely how such a justification achieves arguments of auto-defense, of criticism of said demand, as well as incorporating arguments from the progressive world. Despite its robustness and after a careful evaluation, it is concluded that this justification is nor sustainable under rational means.
\end{abstract}

Keywords: Gay marriage; legal system; justification; recognition; liberalism. 


\section{CONTROVERSIA, SILOGISMO DE LA IGUALDAD Y EXIGENCIA DE JUSTIFICACIÓN}

Las posiciones que disputan en torno al reconocimiento jurídico del matrimonio entre personas del mismo sexo (en adelante, RJMPMS) coinciden en reglas de exclusión basadas, por ejemplo, en la edad mínima, el grado de parentesco, la vigencia de un vínculo conyugal preexistente o el impedimento mental. La diferencia se genera en torno a otra cuestión: ¿en qué medida la discriminación -que supone la definición de matrimonio (presente normalmente en los códigos civiles de los distintos países) basada no única pero sí esencialmente en la diferencia sexual y la orientación a la procreaciónes (o no) arbitraria? Esa diferencia puede traducirse en una oposición jurídica, puesta en evidencia en muchos países, entre, de una parte, las constituciones políticas o cartas fundamentales, que establecen los principios igualitarios y de no discriminación arbitraria (así como también conceptos de familia que no precisan géneros) y, de la otra, los respectivos códigos civiles, donde radica la cuestionada definición de matrimonio - esto es, un contrato solemne por el que un hombre y una mujer se unen por toda la vida con la finalidad de acompañarse, auxiliarse mutuamente y procrear $^{1}-$.

La demanda por el RJMPMS puede ser reconstruida así: primero, se pone como premisa mayor a la Constitución, en tanto garantía de los principios de igualdad y no discriminación arbitraria. Segundo, se considera al Código Civil como un texto que contradice dichos principios y que -al excluir del matrimonio a las personas del mismo sexo- permite una forma de trato desigual y discriminatorio. Tercero, se instala un escenario político de verificación según los siguientes términos: si el Código Civil tiene razón, entonces, es preciso eliminar los artículos igualitarios de la Constitución. Si, al contrario, se conserva el artículo constitucional igualitario y antidiscriminatorio, entonces, se hace necesario reformar el Código Civil. Visto así, la demanda por el RJMPMS interpela radicalmente del modo siguiente: de una parte, exige transformar un ordenamiento jurídico y social considerado como no igualitario y discriminador (encarnado en el Código Civil). Pero, de otra, implica que, de no ocurrir esto, se ponen en cuestión los propios principios de igualdad y no discriminación amparados constitucionalmente ${ }^{2}$.

Así de radical es la demanda, y así de fundamental es la exigencia de justificación a los opositores. ¿Negarán ellos los principios constitucionales de igualdad y no discriminación? Ellos quedan obligados a mostrar que lo que se les presenta como una

\footnotetext{
${ }^{1}$ Ambos textos expresan tradiciones jurídicas occidentales, de ahí que sea posible hacer una generalización. Las constituciones contienen cláusulas igualitarias fundadas en la propia Revolución Francesa. El Código Civil expresa definiciones del derecho romano, canónico y del Código Civil francés, todos de gran influencia en los códigos de muchos países (Guzmán, 2005; Tapia, 2005).

2 Jacques Rancière (2004) se refiere a esta lógica como "silogismo de la emancipación". Ver Basaure (2002a). 112 | AlPHA № 52 (JuLIO 2021) PÁGS. 111-131. ISSN 07 16-4254
} 
contradicción, no lo es realmente; es decir, que es posible asumir afirmativamente los principios constitucionales de igualdad y no discriminación y, simultáneamente, defender que las parejas homosexuales no sean tratadas como iguales en cuanto al matrimonio. Detractores del RJMPMS reconocen lo radical de esa exigencia cuando buscan que el concepto de familia, presente en las constituciones, coincida con el de los códigos civiles, para ello se busca definirla también constitucionalmente como vínculo heterosexual (Basaure, 2015b). Lo mismo acaece cuando señalan que la exigencia de igualdad de derechos en las sociedades modernas tiene un carácter inflacionario y extralimitado (ver Glendon, 1991). Pero el desafío de justificación permanece: conjugar Constitución y Código Civil; igualdad y no discriminación arbitraria, por un lado, y discriminación efectiva, por el otro ${ }^{3}$.

Planteado en términos estrictamente lógicos de lo anterior se deduce los siguiente: quienes discriminan deben justificar que la discriminación es justa o no arbitraria. Plantearlo de otro modo tiene poco sentido pues, en términos formales, pedirle justificación a quien exige derechos de igualdad en este caso, no es distinto a haberlo hecho con alguien discriminado en un contexto segregacionista racial. En concreto, opositores al RJMPMS han dado justificaciones robustas que, en principio, podrían sustentar el carácter no arbitrario de la discriminación en este caso. Se entiende por robusta no necesariamente una argumentación teóricamente más coherente, sino aquella que logre movilizar más argumentos, aceptables en sociedades plurales y diversas, tanto de autodefensa como de crítica hacia la demanda por el RJMPMS.

\section{LA ESTRUCTURA ELEMENTAL DE LA JUSTIFICACIÓN OPOSITORA}

Para calificar una discriminación como no arbitraria debe existir una justificación razonable. No lo es la mera reafirmación o iteración de la definición heterosexual de matrimonio, presente en muchos de los códigos civiles. Pensarlo de otro modo supondría validar -como en el iuspositivismo kelseniano, radicalizado por Luhmann (1969)-que la legitimidad del derecho reside en el propio texto jurídico, cuestión que niega el espíritu de la propia idea de "justificación razonable". Esta apela a la noción de buenas razones extrajurídicas y supone, con ello, un doble nivel analítico, propio de las teorías normativas del derecho: $i$ ) la legitimidad de la norma jurídica, orientada a reglar universalmente y con capacidad coercitiva nuestra vida en común, ii) se sustenta en una justificación con

\footnotetext{
${ }^{3}$ Aunque ese esfuerzo de justificación no sea la última palabra, sí es absolutamente necesario. La doctrina separate but equal buscó sortear la contradicción entre discriminación y principio igualitario. Esa doctrina permitió en U.S.A. instaurar, por varias décadas, un régimen de segregación racial. Las anti-miscegenation laws prohibieron y criminalizaron el matrimonio interracial. Esa doctrina se llevó a cabo sin supuestamente violar el principio constitucional igualitario de la decimocuarta enmienda. Ese esfuerzo no fue la última palabra: dicho régimen, abolido hace más de sesenta años, es recordado únicamente como parte de la inadmisible historia del racismo. ¿Ocurrirá lo mismo en las próximas décadas con las leyes que hoy impiden el RJMPMS?
} 


\section{Mauro Basaure}

pretensiones de validez universal ${ }^{4}$. ¿Cuál es esa justificación extrajurídica para los detractores del RJMPMS?

De una misma estructura argumental pueden reconstruirse dos vertientes que aspiran a dar dicha justificación; siendo solo una de ellas robusta, en el sentido recién mencionado. Esa estructura puede derivarse de un análisis del propio lenguaje ordinario: se suele decir "el matrimonio es entre un hombre y una mujer". Por ordinaria que sea, esta frase esconde un doble sentido: esencial y sociohistórico institucional. El primero alude al ser de las cosas en sí mismas; el segundo, refiere a lo que los hombres construyen socialmente: las leyes, por ejemplo. En ambas vertientes se afirma la necesidad de que ambos sentidos coincidan, constituyéndose así la verdad del matrimonio. Este debe ser en su doble sentido: debe ser lo que "es". No es una tautología sino un esfuerzo por fijar lo contingente a lo concebido como necesario (Boltanski, 2009; Basaure, 2015a): ello depende de que se reconozcan institucionalmente los elementos excluyentes de la definición tradicional de matrimonio: un vínculo entre un hombre y una mujer (monogamia y diferencia sexual), orientado a la procreación. La definición jurídica del matrimonio contiene otros elementos -no excluyentes; relacionales, como el amor, la afectividad, el cuidado mutuo; elementos difíciles de cohesionar y que el matrimonio busca mantener unidos, haciéndola una institución compleja (Browning, 2003)-, pero solo si contiene dichos elementos excluyentes se trata de un verdadero matrimonio.

En ambas variantes opositoras al RJMPMS, la institución matrimonial obtiene un carácter objetivo, independiente de las preferencias e inclinaciones personales. El verdadero matrimonio no tiene ningún potencial de maleabilidad cultural o de racionalización normativa. Sancionado jurídicamente, no es relevante por qué una persona o pareja quiere contraerlo, si quiere o no tener hijos, etc. Más bien se accedería a un espacio de acción e interacción objetivado, cuyo marco legal expresaría una realidad prelegal. El matrimonio es una reunión compleja de bienes distintos y dispares, no separables; de modo que se pueda elegir tomar algunos (la afectividad, por ejemplo) y no otros (la procreación, por ejemplo) (Browning y Marquardt, 2006). El verdadero matrimonio además supone una jerarquía de esos bienes, siendo la diferencia sexual y la procreación jerárquicamente superiores al afecto o el cuidado. Ese matrimonio no discrimina porque un ser encarnado o una institución política jurídica lo diga, sino simplemente porque es lo que "es".

Si lo anterior constituye la estructura del argumento normativo, no ofrece aún el fundamento. En esa estructura se reconoce, por ejemplo, la tradición del derecho natural, pero no aun el contenido de ese derecho. La pregunta es aquí ¿por qué el matrimonio sociohistórico institucional debe coincidir con el matrimonio esencial?

\footnotetext{
${ }^{4}$ Este doble nivel analítico se expresa disciplinariamente: la discusión no puede ser puramente jurídica; entra en escena la filosofía política, por ejemplo, orientada a evaluar el carácter moral de las justificaciones.

114 | AlPHA № 52 (JuLIO 2021) PÁGS. 111-131. ISSN 07 16-4254
} 


\section{DOS VERSIONES DE LA JUSTIFICACIÓN CONSERVADORA}

La respuesta a dicha cuestión establece la dimensión normativa en términos no de la estructura del argumento, sino de su contenido. En relación con este se pueden distinguir analíticamente dos variantes ${ }^{5}$, una que apela a la idea de bienes humanos y otra que se identifica con el resguardo del bien común y el futuro de la comunidad. Conviene evaluar la propiedad de robustez que poseen.

La primera de las variantes aludidas refiere directamente a las versiones clásicas y modernas (new natural law) del derecho natural, basadas en la tradición aristotélico tomista, aunque hacen interpretaciones bien distintas de esta tradición: en un caso de orden metafísico y en el otro práctico cognitivo. La versión clásica deduce de la naturaleza humana ciertos fines que realizan al ser humano e identifica inclinaciones cuyo sentido está dado por tales fines. La unión conyugal entre hombre y mujer es una de esas inclinaciones naturales, pues en ella los seres humanos se realizan. Este sería el contenido esencial y normativo que tendría la ley de matrimonio del Código Civil. La fuerte petición de principio que hace esta visión clásica iusnaturalista la torna improcedente y débil como justificación en el contexto de sociedades plurales como la nuestra.

En parte por lo mismo las versiones modernas del derecho natural buscan alejarse de contenidos religiosos esperando encontrar eco en un público secular (Massini-Correa, 2014). Finnis (1996, 1997), representante más destacado de la new natural law, desplaza el punto de partida desde uno ontológico-metafísico a uno de orden epistémico o gnoseológico. El contenido del derecho natural se establece aquí mediante una indagación cognitivo práctico-teleológica de los bienes humanos básicos en tanto que objetos de las inclinaciones humanas. Salvo el desplazamiento del punto de partida inicial, y con ello el método de fundamentación, no se ven alterados los resultados. El ejercicio recuerda la tesis de la filosofía de la historia de Walter Benjamin (2010), donde la teología, consabidamente, vieja y fea, no debe dejarse ver, lo que no significa que no siga operando.

Con este desplazamiento, el new natural law logra superar la falacia naturalista, que afecta irremediablemente a la posición clásica, pero ello no necesariamente establece las condiciones para participar en la discusión pública en sociedades plurales. Finnis (1997), de hecho, coincide uno a uno con la tradición clásica en la identificación de los bienes humanos, entre ellos el del matrimonio heterosexual, y de este modo con las formas tradicionales de la cosmovisión cristiana. Ello incluye la consideración de la sexualidad homosexual como inmoral, e incapaz de expresar reconocimiento y amor, de modo que aceptaría ser comparada con la masturbación o el sexo con prostitutas; incluye

\footnotetext{
${ }^{5}$ Los análisis posteriores se basan en gran medida en los siguientes libros: Basaure y Svensson, 2015; Corvino y Gallagher, 2012; Rimmerman y Wilcox, 2007; Sullivan, 1997; Wardle et al., 2003.
} 


\section{Mauro Basaure}

además una oposición a cualquier forma de reconocimiento institucional de relaciones homosexuales (no solo bajo la figura del matrimonio), pues ello sería validar algo inmoral, que además sería hostil e injurioso para parejas heterosexuales que valoran el matrimonio. Estos contenidos son difícilmente expresables en las esferas públicas de sociedades plurales, salvo cuando se encuentran devaluados los principios democráticos $\mathrm{y}$ de los derechos humanos.

El cognitivismo de Finnis (1996) no pone en cuestión la referencia a la primacía ontológica de una naturaleza humana, definida en los términos tomistas clásicos, sino solo el que la inferencia acerca de dicha naturaleza sea un camino válido en la especificación del contenido normativo del derecho natural (Massini-Correa, 2014). Sin esa primacía, las inclinaciones humanas básicas podrían ser entendidas en términos instrumentales o funcionales, cuestión, en principio, no incluida en esta perspectiva. Tanto en su versión clásica como moderna, de hecho, el matrimonio, como unión de cónyuges de diferente sexo, es considerado un bien en sí mismo; esto es, no es defendido por su función. Junto con ello, la procreación aparece ahí no como fin externo, sino como un don que sobreviene intrínsecamente de esa unión cuando ella se actualiza sexualmente (George, 2006).

En este punto puede introducirse la segunda de las variantes, pues ella, a diferencia de la anterior, opera en términos funcionales. Esta versión tiene un cariz más pragmático y heterodoxo y no es posible asociarla directamente con un autor en particular. Es reconstruida aquí en términos típico-ideales, en sentido weberiano (Weber, 1995). No solo un daño simbólico parcial (por ejemplo, hacia quienes valoran y optan por el matrimonio heterosexual), sino que un perjuicio al bien común y a personas concretas, es lo que está en el centro de esta argumentación. Según ella, la unión sexual entre personas de distinto sexo produce niños; para su sana reproducción en el tiempo, la sociedad los necesita, por lo que la diferencia sexual debe ser protegida y reconocida institucionalmente. Además, dice este argumento, los niños, para desarrollarse adecuadamente, requieren de su padre y su madre. Esta noción de hijos psicológicamente sanos, base para la reproducción de una sociedad sana en el tiempo, está en el núcleo del argumento.

Las dimensiones de la procreación, de una parte, y de la crianza, de otra, están involucradas como cuestiones externas. El argumento, además, involucra (por negación) una lógica del daño. El matrimonio entre personas del mismo sexo es perjudicial sobre todo para los niños y, con ello, para la sociedad. El argumento busca responder a aquella razón liberal que, desde J. S. Mill a Rawls, es identificada como la única por la que puede establecerse una prohibición a los individuos: la prevención del daño a un tercero, que traduce aquí la cuestión de los límites de la propia libertad. En principio, el argumento opositor refiere a esta posibilidad y prevención, y solo a ella e intenta, por tanto, dar buenas razones contra el RJMPMS, cuestión que la diferenciaría de la variante para la 
cual esa prohibición tiene como fundamento una trasgresión a la naturaleza humana o a bienes humanos básicos.

$\mathrm{El}$ argumento deriva su carácter normativo de su lógica funcional. El matrimonio se define en relación con su efecto en los nuevos individuos de la sociedad y el conjunto de esta. El qué es se traduce como qué función cumple. La estructura formal básica de la justificación opositora se mantiene intacta pero el matrimonio tiende a "desesencializarse" y entenderse según su relevancia funcional ${ }^{6}$. Los componentes del argumento se concatenan causalmente; ninguno es presentado como normativo. El deber ser aparece solamente si se quiere la reproducción sana de los miembros de la comunidad $\mathrm{y}$, con ello, de la propia comunidad. Solo si se quiere esto, entonces, se debe querer necesariamente un matrimonio definido -no única, pero esencialmente- sobre la base de la diferencia sexual y de la orientación a la procreación. Se trata de un deber ser de las condiciones necesarias ${ }^{7}$. Esos contenidos, concatenados según una lógica funcional, establecen la fuerza normativa del argumento: si el Estado tiene efectivamente una preocupación por la sana perpetuación de la comunidad, entonces el matrimonio jurídico institucional debe coincidir con el matrimonio esencial. Las reglas de acceso excluyentes, estatalmente establecidas, tendrían como justificación, por tanto, asegurar jurídicamente la especificidad del matrimonio. La discriminación en cuestión sería, por ello, no solo noarbitraria y legítima, sino también necesaria.

\section{ROBUSTEZ COMO AUTODEFENSA DE LA JUSTIFICACIÓN INSTRUMENTAL FUNCIONAL}

Arriba se afirmó que solo esta última variante puede ser considerada robusta, en el sentido de la capacidad de movilizar argumentos, aceptables en sociedades plurales y diversas, tanto de autodefensa como de crítica contra el RJMPMS. En este apartado se busca dar sustento práctico a dicho juicio de robustez.

\section{a. Defensa frente a la crítica de la homofobia, intolerancia y tradicionalismo}

Ni contenidos homofóbicos, ni alguna forma de intolerancia o de tradicionalismo pueden serle achacadas al argumento opositor, cuya justificación se basa en la defensa neutral del bienestar individual y la reproducción del colectivo. La variante instrumental y funcional del argumento opositor se defiende de tres críticas: la primera es la crítica de homofobia. Esta crítica sería improcedente, pues el argumento no se sustentaría en ningún prejuicio, ni contra las personas homosexuales ni contra sus relaciones amorosas o sexuales. De hecho, no es incompatible con la crítica a la discriminación y el prejuicio

\footnotetext{
${ }^{6}$ Para un análisis de la figura opuesta, de un funcionalismo crítico, ver Basaure (2011).

${ }^{7}$ No es un deber ser de orden kantiano o teológico (sollen) que valga por sí mismo, independientemente de la intencionalidad de los actores. La normatividad emerge solo de la conjunción de relaciones no normativas. Es, en palabras de Stemmer (2008), un deber ser de las condiciones necesarias.
} 


\section{Mauro Basaure}

contra los homosexuales. Más aún, se puede apoyar la causa homosexual en todos aquellos ámbitos donde no esté en juego el matrimonio ${ }^{8}$.

Esto constituye una diferencia clave con la variable iusnaturalista aristotélico tomista. Ello se extiende a la crítica de intolerancia, igualmente desacertada respecto de la variante instrumental funcional. No es porque se considere que las parejas homosexuales y sus relaciones sexuales sean reprochables en algún sentido (según una ética religiosa o secular), que ellas no se pueden casar. El fundamento de esta prohibición reside solo en la ausencia de la diferencia sexual capaz de procreación y del medio perjudicial que constituirían para la crianza. A excepción de ello, no hay nada extra que pueda ser invocado como razón para oponerse al RJMPMS.

Errada estaría también la crítica del tradicionalismo o conservadurismo: la oposición al RJMPMS no se basa en el argumento de la duración histórica del matrimonio heterosexual; es decir, en el pésimo argumento que pregunta por qué revisar lo que ha sido así desde tanto tiempo. La tradición tiene aquí más bien un estatus equivalente a la ley. Si lo que la tradición, avalada religiosa o secularmente, porta consigo, de una parte, y lo que señala el cuerpo jurídico de una sociedad respecto del matrimonio, de la otra, coinciden con el matrimonio esencial, es porque esa tradición y esa ley no se han alienado (aun) de la realidad esencial y objetiva del matrimonio y no han derivado al terreno de lo arbitrario. El argumento no niega que la tradición y la ley sean realidades convencionales e histórica y socialmente determinadas; solo afirma que pueden también ser no arbitrarias en tanto expresen una suerte de racionalidad práctica (Browning, 2008), basada en experiencias reales del funcionamiento del mundo, la condición humana, y de lo necesario para su mantenimiento. Si, desde este argumento, por tanto, se avalan ciertas tradiciones religiosas o seculares, no es como tales -no es por tradicionalismo-, sino porque su contenido expresa esa coincidencia entre ontología y tradición ${ }^{9}$. Esta última defensa puede ser reclamada, valga decirlo, tanto por la variante del nuevo derecho natural, basada en la noción de bienes humanos, como por la variante instrumental funcional, que apela a la defensa contra el daño individual y colectivo.

\section{b. Crítica al individualismo, los derechos y el liberalismo}

Según la estructura del argumento opositor al RJMPMS, este pone en juego la coincidencia entre matrimonio esencial (lex aeterna (Oeser, 2004)) e institucional. Es posible que la libertad que se arrogan los individuos conduzca a que no exista tal

\footnotetext{
${ }^{8}$ Los detractores del RJMPMS pueden, al mismo tiempo que afirmar las leyes antidiscriminación, negar que ellas puedan ser invocadas por parejas homosexuales frente a los tribunales para reclamar discriminación arbitraria en relación con el matrimonio civil.

${ }^{9} \mathrm{Si}$, en principio, Finnis puede presentar esta defensa contra la crítica de tradicionalismo, como se ha visto arriba, la crítica de homofobia e intolerancia le resulta inescapable.
}

118 | AlPHA № 52 (JuLIO 2021) PÁGS. 111-131. ISSN 07 16-4254 
coincidencia; a que el vínculo parental preestatal -que al Estado le cabe solo reconocersea anulado (olvidado) por constructos jurídicos creados por los hombres (Farrow, $2007)^{10}$. Ciertos procesos socioculturales en las sociedades modernas fomentan una ruptura creciente entre esencia e institución. Al respecto, hay tres argumentos típicos, emparentados entre sí. Uno de orden sociohistórico: el individualismo exacerbado de las sociedades modernas; otro de orden jurídico: la expansión de la retórica de los derechos subjetivos; y uno de carácter filosófico: la supuesta hegemonía del pensamiento liberal. Estas críticas pueden ser esgrimidas tanto desde las versiones iusnaturalistas del matrimonio esencial como desde aquella instrumental, pero solo esta última puede además establecer ciertas concesiones que la hacen en principio más robusta.

El individualismo, que impone la libertad individual como medida de todo, conduce a un olvido de las limitaciones naturales del género humano y de las condiciones de la reproducción de la comunidad. Encamina a una trasgresión al generar la ficción de que lo que no depende del individuo, sí depende de él. Predispone a la evasión del principio de realidad. La lógica expansiva del individualismo se expresaría en una comprensión colonizadora de los derechos subjetivos, a partir de la que se levantarían demandas injustificadas, como aquella por el RJMPMS. En la versión instrumentalista robusta, el argumento opositor, sin embargo, no se presenta completamente incompatible que parejas homosexuales puedan adquirir el estatus de uniones civiles. Siguiendo con la dicotomía entre lo público y lo privado, y considerando que esas relaciones tienen relevancia puramente privada, ellas pueden ser reguladas y protegidas mediante el derecho privado, no contraviniendo nada fundamental. Se propone así una lógica de dos mundos: lo privado se conjuga con la unión civil, y lo público con el matrimonio ${ }^{11}$. Separate but equals. Incluso más; que la legislación no les otorgue a parejas homosexuales el estatus de unión civil, podría ser visto -desde la variante instrumental del argumento opositor-como una discriminación arbitraria. Las parejas homosexuales, en todo caso, deberían ser protegidas bajo un marco legal distinto al del matrimonio, pues sería injusto que para protegerlas se recurriese al mismo marco legal destinado a las parejas heterosexuales, cuya función social objetiva es de primera importancia.

Afín a lo anterior, según este argumento, se denuncia al liberalismo como la base ideológica de la destrucción de los cimientos institucionales de la reproducción sana del colectivo. Aquel promovería irresponsable y equivocadamente los principios de igualdad y no discriminación en ámbitos no pertinentes, en orden a fundar una institucionalidad que, basada en el principio de neutralidad, eximiría al Estado de la tarea pública de responsabilizarse por las condiciones de reproducción de la vida humana. Según esos principios, se elimina la posibilidad de que lo igual sea tratado como igual y lo diferente como diferente. Se olvida que la diferencia entre parejas de igual y distinto sexo refiere a

\footnotetext{
${ }^{10}$ También se habla de la ruptura entre lo simbólico y lo cultural (o histórico e institucional). Ver: Schneider (2005).

${ }^{11}$ Martha Nussbaum (2010) ha propuesto precisamente lo contrario. Ver más abajo.
} 


\section{Mauro Basaure}

su relevancia pública: la capacidad objetiva que tienen o no de aportar al bien común. Ni el afecto, ni menos la sexualidad en sí, sino la sexualidad procreativa y la diferencia sexual como medio de crianza, sería lo único de interés público.

Ante y contra estas tendencias sociales, jurídicas y filosóficas, el Estado debe impedir la privatización de cuestiones que, por su relevancia social, no son ni deberían ser privatizadas. El análisis de la demanda por el RJMPMS y de sus bases de sustentación (sociales, jurídicas y filosóficas) muestra que la crítica a ella tiene dos niveles: $i$ ) La demanda sería particularista e irresponsable respecto del bien común, ii) pero se encontraría engañosamente alojada y justificada en los términos universalistas de la primacía de los derechos humanos y del liberalismo, y de los consecuentes principios de la igualdad, la no discriminación y la neutralidad del Estado.

La robustez de esta variante se pone de manifiesto también en su capacidad de afirmarse en discursos, en principio, extraños; puede establecer conexiones inesperadas con discursos considerados de izquierda política ${ }^{12}$. En particular, la crítica opera según la conocida denuncia, propia del comunitarismo, que intenta develar lo particular en lo pretendidamente universal, asumiendo para ello que lo único universal aquí es la preocupación por el daño individual a terceros y a las condiciones de la sana reproducción de la comunidad ${ }^{13}$.

\section{c. Incorporar el discurso adversario: la crítica queer y el liberalismo}

Lo recién dicho se complementa con la incorporación de la perspectiva del adversario para alimentar la suya propia, cuestión que es otra muestra de robustez del argumento opositor. Efectivamente, este puede encontrar sintonía tanto con la perspectiva queer como con cierta versión del liberalismo.

Junto con oposición a la equivalencia jurídica que implica el RJMPMS, los opositores a este acusan que dicho reconocimiento constituye en realidad una mera fachada. Más que dicha equivalencia (según la que dos o más objetos diversos se equivalen por un tercero, que es la ley (Basaure, 2002b)) se buscaría una

\footnotetext{
${ }^{12}$ Los detractores del RJMPMS pueden encontrar referencias en todos los discursos críticos del liberalismo, tanto en su versión política como económica. Por lo mismo, no es difícil encontrar referencias al marxismo, la socialdemocracia, el comunitarismo, la crítica ecológica, y sus esfuerzos por limitar el ámbito de acción individual y del mercado en función de la defensa de bienes públicos. Es un error, por ello, inscribir esta controversia en el eje izquierda-derecha.

${ }^{13}$ Además, el falso universalismo sobre el que se levantaría la demanda igualitaria presenta el problema de que -precisamente por su pretendida universalidad y carácter moral- se muestra como una ortodoxia, una última instancia de la argumentación que no solo eximiría indebidamente de una mayor fundamentación, sino que también permitiría una moralización del oponente. Una denuncia schmittiana acusa que los defensores del RJMPMS, al apoyar una demanda particularista e irresponsable para con el colectivo, se permitirían la denostación moral de sus adversarios y destruir el debate de ideas, el carácter político de esta controversia.
} 
homogeneización: no la exigencia de un trato jurídicamente igual, sino el ser tratados como "lo mismo" en sentido sustantivo. Las parejas homosexuales no quieren en realidad el nuevo matrimonio sino el tradicional, heterosexual, porque quieren ser como las parejas heterosexuales, hacer como si fuesen heterosexuales ${ }^{14}$. Paradójicamente, la perspectiva queer, para la que la demanda de RJMPMS es heteronormativa (Eisenstein, 2009), nutre esta crítica. Por opuestos que sean, opositores al RJMPMS y teóricos queer, coinciden en entender que esa demanda reafirma el matrimonio heterosexual. En este marco se interpreta igualmente el deseo de las parejas homosexuales de tener hijos: complementando el matrimonio con el derecho a la adopción, la reproducción asistida y los vientres de alquiler se querría imitar la misma naturaleza.

Ahora, en lo relativo a la equivalencia jurídica, el RJMPMS generaría un falso reconocimiento en dos sentidos: por un lado, las parejas heterosexuales serían despreciadas simbólicamente y pasarían a ser consideradas meras relaciones afectivas dejando además de contar con una protección legal propia y específica, que dignifique su rol y contribución al bien común. Por otro, las parejas homosexuales serían también falsamente reconocidas en un sentido contrario: valoradas por algo que no son. Poniendo como criterio de equivalencia el compromiso relacional afectivo, se pierde de vista el criterio diferenciador (el aporte al bien público). La verdadera diferencia se anula mediante una ficción jurídica. Ello trae consigo varias consecuencias. Primero: no se trata de que el mismo matrimonio crezca por inclusión de nuevos miembros elegibles, sino que se produce una transformación sustantiva y radical de él. Se trata ahora de dos cosas distintas por naturaleza. Segundo: la nueva institucionalidad matrimonial destruye la existente. Si a la nueva institución se la llama matrimonio, debería entonces cambiársele nombre a aquella que sí coincide con el matrimonio esencial. Tercero: la demanda por el RJMPMS, paradójicamente, se autoelimina. En el mismo momento en que accede a lo buscado, se queda con las manos vacías, pues lo que conquista no es lo que quería conquistar. Se accede al matrimonio, pero este ahora no vale nada públicamente relevante.

La equivalencia jurídica a base de nociones relacionales y no procreacionales y de crianza, conducen a que no sea posible discriminar -o sería de arbitrario hacerlorelaciones afectivas, sexuales y no sexuales, como las amistosas, fraternales, familiares no tradicionales, etc. Con ello, lo intrínsecamente público deviene privado y lo intrínsecamente privado deviene artificialmente público, en el sentido de estatalmente sancionado. Esto suscita una consecuencia radical: por coherencia, el Estado -cuyo ámbito de acción refiere a la cosa pública- debería alejarse del negocio del matrimonio. Si se ha dado el paso en favor del RJMPMS, en atención al significado y consecuencias que esto implica, por coherencia, se debería avanzar en abolir el matrimonio estatalmente regulado. Esta es la respuesta más radical de los detractores frente a la demanda igualitaria

\footnotetext{
${ }^{14}$ Este argumento obvia el hecho sociológico de que heterosexuales y homosexuales son socializados bajo expectativas e ideales equivalentes en relación con el parentesco y la familia (Green, 2006).
} 


\section{Mauro Basaure}

del RJMPMS. Las uniones civiles debiesen, por tanto, constituir la única instancia legítima para regular la vida en pareja.

Así, los detractores del RJMPMS llegan inesperadamente a coincidir con aquellos liberales que, por razones muy distintas, también concluyen que el Estado -si quiere ser coherente con sus principios- debe alejarse del negocio matrimonial. Nuevamente los adversarios se toman de la mano. La cuestión liberal no refiere a criterios de elegibilidad y puesta en equivalencia ${ }^{15}$, sino al hecho de que un tipo de relación sea reconocido jurídicamente por el Estado como matrimonio, otorgándole injustificadamente una dignidad especial y con ello la repartición de menores dignidades a formas de vínculo no matrimoniales, y transgrediendo así el principio de neutralidad y no discriminación frente a las diferentes formas de vida. De ahí que algunos liberales concluyan -desconociendo la propia demanda por el RJMPMS- que una alternativa sería que el matrimonio se le dejara a la Iglesia y las uniones civiles al Estado, pues estas últimas permiten asegurar universalmente un régimen de beneficios y evitan que el Estado pierda su neutralidad (Nussbaum, 2010) ${ }^{16}$. Un problema de este argumento es que, siendo afín con el liberalismo, no lo es con la demanda por el RJMPMS, pues significa una nivelación hacia abajo y no hacia arriba como esa demanda pretende (Mascareño, 2015).

La posición liberal subvierte un supuesto que está en la base de la controversia abierta por la demanda por el RJMPMS: que el Estado tiene un legítimo rol regulador en relación con el matrimonio. Esta posición liberal, o carece de relevancia con relación a esa demanda en específico o se hermana con la posición detractora proveniente del conservadurismo. Hay un argumento con el que el liberalismo puede sortear este

\footnotetext{
${ }^{15}$ Considerando la dimensión de los criterios de elegibilidad podrían identificarse teóricamente al menos dos posturas. La primera vertiente acusa que el RJMPMS resuelve el problema para parejas homosexuales, pero no para otras parejas que quedarían igualmente excluidas, sin que exista una justificación legítima para ello. La institución matrimonial se haría menos excluyente, pero no mucho más que eso, pues lo seguiría siendo. En este punto, la crítica del liberalismo coincide vis-à-vis con la crítica de los detractores de tal reconocimiento: ambas ponen en cuestión la estabilidad de los criterios de elegibilidad. Para los mencionados detractores, el criterio que abre la posibilidad del RJMPMS permite algo más inaceptable aún: que además de las homosexuales, otras formas de relación puedan también ser elegibles para el matrimonio. Para los liberales es precisamente esta apertura lo que resulta exigible. Una segunda vertiente exige que sean los propios criterios de elegibilidad o pertenencia los que sean abolidos. De ese modo se elimina la discriminación que contiene todo criterio de selección y equivalencia. Hasta qué punto ello es posible, sabiendo que los criterios en cuestión no son solo los excluyentes y no excluyentes, reseñados arriba, sino también aquellos relativos al mínimo de edad, el parentesco, la vigencia de otro matrimonio, entre otros. Esa es una cuestión que debe quedar abierta aquí.

${ }^{16}$ Derrida (2004) hizo esta propuesta en su última entrevista. Si una pareja homosexual quiere contraer matrimonio, lo puede hacer por la iglesia. El Estado le ofrecerá en todo caso la posibilidad de un pacto civil. El argumento se puede extremar: respecto del matrimonio, que sean las iglesias, los clubes privados, etc., los que lo sancionen y celebren, del modo que quieran, según los criterios de elección que gusten, basados en los principios y nociones de finalidad que les parezca. Como no se deben al principio de neutralidad, pueden establecer diferencias de dignidad entre formas de vida alternativas (Thaler y Sunstein, 2008)
}

122 | AlPHA No 52 (JuLIO 2021) PÁGS. 111-131. ISSN 07 16-4254 
problema: si el Estado insiste en inmiscuirse en la cuestión del matrimonio y, por tanto, no cumple, como debería, con el principio de neutralidad, al menos, como cuestión mínima, debe reconocer jurídicamente el RJMPMS. He aquí la diferencia insalvable entre el argumento liberal de la neutralidad del Estado y la variante opositora al RJMPMS, basada en la noción de bien público, para esta es precisamente la no neutralidad y discriminación del Estado respecto de las parejas elegibles para el matrimonio, lo que hace que el Estado cumpla verdaderamente su labor pública. Para los liberales, por el contrario, son los principios de neutralidad y no discriminación los que, independientemente de las consecuencias, constituyen la base de la legitimidad del Estado. La discusión suele agotarse en la pugna de estas posiciones irreconciliables.

\section{EVALUACIÓN CRÍTICA DE LA VARIANTE ROBUSTA DE LA JUSTIFICACIÓN CONTRA EL RJMPMS}

Siguiendo una argumentación puramente lógica, se partió mostrando la obligatoriedad de justificación que pesa en los opositores al RJMPMS. Mediante una metodología de reconstrucción inmamente se expuso ampliamente la justificación más robusta de esos opositores: la variante instrumentalista. Esa justificación debe ahora ser evaluada.

El contenido normativo de la justificación instrumentalista puede llamarse normatividad de las condiciones necesarias. Eso significa que ella se construye a base de la siguiente noción instrumental funcional: si se quiere $X$ entonces es necesario $Y$. Si una comunidad quiere reproducirse sanamente en el tiempo y no dañar a sus nuevas generaciones $(X)$, entonces debe restringir jurídicamente el matrimonio a la diferencia sexual $(Y)$. Así planteado, este argumento constituye una petición de principios. Implica aceptar que para alcanzar $X$ no hay más alternativa que $Y$; es decir, que $Y$ es condición necesaria para $X$. Pero, evidentemente, esta es una afirmación compleja cuya pretensión de validez - en apariencia y principio- es la verdad, la que, sin embargo, depende de lo verdadero de las afirmaciones que la componen. Es una afirmación compleja, pues supone varias afirmaciones en sí no normativas, cuya verdad debe ser empíricamente comprobada. Junto con ello, algunas de esas afirmaciones refieren a la procreación y otras a la crianza: las parejas heterosexuales son las únicas capaces de procreación; las condiciones de procreación heterosexual generan niños psicológicamente sanos; las condiciones de crianza heterosexual generan niños psicológicamente sanos. Así presentado el argumento, se hacen identificables los problemas irresolubles que contiene; los que pueden analíticamente identificarse en relación con cada una de esas afirmaciones.

La primera de estas afirmaciones es, sin duda, verdadera. Parejas homosexuales en tanto tales no son capaces de procreación. El problema de esta afirmación no reside en su pretensión de verdad sino en que dicha capacidad falla inapelablemente como criterio de discriminación. Según ese criterio, también deberían ser excluidas parejas de la tercera 


\section{Mauro Basaure}

edad, ciertas personas minusválidas y aquellas con impotencia perpetua e incurable. Ninguna de ellas puede procrear y, por tanto, aportar a la reproducción material de la sociedad o, según el argumento aristotélico tomista, realizar el fin del matrimonio. Pero de ellas, solo las parejas homosexuales no pueden acceder al matrimonio.

Se trata de salvar este criterio diciendo que en el caso homosexual el impedimento es esencial, mientras en el heterosexual accidental, y que en este siempre está la potencia generativa (Finnis, 1997). Es evidente que esta diferencia no tiene efectos relevantes de fundamentación normativa, y se mantiene que, para salvar el criterio de la procreación, habría que excluir también a todas las parejas mencionadas. De hecho, hasta no hace mucho, en varios países, quienes sufrían de impotencia perpetua e incurable no podían contraer matrimonio. Esta disposición, heredada del Derecho Canónico, fue eliminada porque ponía en cuestión el matrimonio entre personas con cierta discapacidad física o de la tercera edad. Ello en circunstancias de que no hay disposición excluyente respecto de las primeras ni tope máximo de edad para contraer ese vínculo, y resultaba relativamente impensable imponer una exclusión hacia ellas.

Esto muestra que este argumento sí ha encontrado expresiones jurídicas que, por fallidas que sean, buscaban hacerlo verdaderamente coherente. El precio de esa coherencia parece ser demasiado alto, sin embargo. La exclusión debiese extenderse, de hecho, a parejas heterosexuales en edad reproductiva que acuerden no tener hijos (de las que hay muchas) o relaciones sexuales (como las asexuales). ¿Están dispuestos los opositores al RJMPMS a pagar el precio de dicha coherencia? Pero sin coherencia la discriminación es arbitraria: lo igual (parejas de diferente tipo que no pueden procrear) es tratado de manera diferente, sin razón justificable ${ }^{17}$.

La variante instrumentalista del argumento opositor puede llegar a afirmar que ahí donde un niño es procreado sobre la base de métodos que no coinciden con la sexualidad de los padres - un hombre y una mujer- es, por alguna razón, perjudicado. Ello es poco plausible, salvo que se asuma que las condiciones de procreación (artificiales, por ejemplo) están efectivamente relacionadas con el desarrollo psicológico del niño. Hay voces que señalan que lo que se ve perjudicada es nuestra autocomprensión; la

\footnotetext{
17 Visto este argumento desde el punto de vista de la contribución a la reproducción de la comunidad. La sociedad ha logrado reproducirse sin la contribución de muchas parejas, incapacitadas para tener hijos. En la posición conservadora no existe referencia a datos demográficos, referidos, por ejemplo, a las bajas tasas de reproducción de la población. Considerando que homosexuales son una minoría -como bien lo repite el argumento opositor al RJMPMS-, seguramente ello seguirá ocurriendo sin la contribución de estos. Es difícil pensarlo de otro modo, sin caer en un argumento ficcional. Es posible agregar que, desde la antropología, de hecho, no pocos han argumentado el valor evolutivo de las alianzas homosociales; evidentemente, no en un sentido reproductivo, pero sí en relación con otras funciones de sobrevivencia de los grupos sociales (Muscarella, 2000; Kirkpatrick, 2000). El mundo moderno ha ensombrecido el hecho de que ese tipo de alianzas fueron institucionalizadas desde muy antiguo (Mascareño, 2015).
}

124 | AlPHA No 52 (JuLIO 2021) PÁGS. 111-131. ISSN 07 16-4254 
comprensión de nuestro propio origen (como finito y limitado a la diferencia sexual (Agacinski, 2001)), así como nuestra comprensión del significado de los hijos, cuestión que dañaría la relación con ellos y, de ahí, a ellos mismos. Los hijos dejarían de ser un "don" que sorprende y pasarían a ser seres conseguibles a disposición. Parejas lesbianas que recurren a la donación de esperma o parejas gay que recurren a un vientre de alquiler, por ejemplo, operarían bajo una lógica instrumental adquisitiva (Browning, 2003), basada en un deseo egoísta ${ }^{18}$, donde los hijos son objetos para satisfacer una ficción. El argumento es extraño: por un lado, salvo que se les mienta a los hijos o uno se autoengañe, nadie pretende que el origen sea distinto que el de la diferencia sexual. Pero incluso si aquella crítica tuviese algún aspecto cierto respecto de nuestro desarrollo cultural, ella podría ser aplicable en los mismos términos a parejas heterosexuales que recurren a la procreación asistida y la adopción. Ese es un tema complejo y esencial de la bioética. Nuevamente: la aplicación de este criterio en las condiciones perjudiciales de la procreación debería involucrar también a estas últimas parejas. Nuevamente, el precio de establecer coherencia parece ser demasiado alto, sin embargo, ¿Están dispuestos los opositores a pagar el precio de dicha coherencia? Especificar esta crítica solo en relación con las parejas homosexuales expresa un prejuicio injustificable, que funda una discriminación arbitraria: lo igual (parejas de diferente tipo que recurren a métodos de procreación distintos a la sexualidad heterosexual dentro del matrimonio) es tratado de manera diferente, sin razón justificable. Ese prejuicio hace dudar de la veracidad de las afirmaciones, según las que, como se mostró arriba, la variante instrumentalista del argumento opositor pretende escapar de la acusación de homofobia o intolerancia.

Siguiendo la propia lógica del argumento opositor, este análisis crítico debe trasladarse desde la cuestión de la procreación a la de la crianza. Sin perjuicio de lo dicho arriba, la controversia se concentra, sin duda, en la afirmación que señala que las condiciones de crianza heterosexual generan niños psicológicamente sanos, de modo que la falta de esas condiciones es perjudicial para estos, y con ello, para la sana reproducción de la sociedad. Tres cuestiones, tanto o más problemáticas que las ya reseñadas arriba, ponen en entredicho esa afirmación.

En primer lugar, apelando a un mínimo de coherencia, el argumento opositor debe implicar asimismo un serio cuestionamiento a cualquier forma no tradicional de familia, las que serían realidades fácticas indeseables. Su única validez reside en que ("lamentablemente") existen. Impotente, el Estado no tendría más que asumir el daño, de esta disfuncionalidad, a las nuevas generaciones. Además, quien asume dicho argumento, tiene que concluir en la exigencia del fin a la ley de divorcio. Salvo quienes consideran insuficiente el régimen contractual para sellar un matrimonio y recurren a formas

\footnotetext{
${ }^{18}$ Además de esta lógica adquisitiva, se critica el hecho de la generación de un mercado en el ámbito de la procreación, en el que se ve perjudicada también la persona que se pone a disposición para asistir la reproducción.
} 


\section{Mauro Basaure}

religiosas más exigentes -como el "matrimonio por pacto" (marriage pact) Witte y Nichols (2008) Brinig (2010)-, pocos de los mencionados detractores parecen estar dispuestos, sin embargo, a hacer públicas las consecuencias lógicas de su argumentación.

En segundo lugar, ese argumento viene a quebrar la lógica, arriba expuesta, según la que: mientras el matrimonio se conjuga con lo público y por ello con la regulación estatal, la unión civil lo hace con lo privado. Parte importante de la discusión pública refiere hoy al derecho de adopción por parte de parejas unidas bajo el régimen de unión civil. Asumiendo que puedan llegar a contar con dicho derecho, ellas deberían también ser de relevancia público-estatal, pues estaría en juego la crianza de las nuevas generaciones. No solo se rompe con ello la diferencia público/privado, defendida por el argumento opositor, sino que se establece una exigencia de explicitar su posición respecto de las uniones civiles. El argumento debiese implicar, por tanto, ya sea la negación tajante de la posibilidad de la parentalidad a parejas (heterosexuales y homosexuales) vinculadas bajo el régimen de unión civil, ya sea una iteración de la discriminación entre parejas heterosexuales y homosexuales relativa al matrimonio, ahora respecto de la unión civil. Se trata de un problema serio para el argumento opositor si quiere mantener su mentado respeto de los derechos de parejas homosexuales.

En tercer lugar, esta afirmación de la crianza y el daño ha sido ampliamente refutada por las ciencias empíricas. Lo único comprobable es que un medio marcado por la falta de amor, cuidado y protección resulta perjudicial para el desarrollo de los niños. Las ciencias sociales no se equivocan en definir a dicho medio en términos de una esfera en que opera un tipo especial de reconocimiento (Honneth, 2011) o de un subsistema social con un código propio (Luhmann, 1994). Entre varias cosas, ello significa que, para su buen funcionamiento (proveer recursos afectivos, de cuidado y también de tipo financiero), no es necesaria la presencia de una asociación específica entre roles y género. En todo caso, difícilmente podría argumentarse que parejas homosexuales están menos capacitadas para entregar amor, cuidado y protección que parejas heterosexuales. Argüir de este modo es incurrir directamente en un odioso prejuicio ${ }^{19}$, del que el argumento más robusto de los opositores dice estar libre.

Este argumento no provee ningún recurso contra el hecho de que pedófilos, abusadores de menores, sádicos, y todos quienes sí ponen en riesgo el bienestar e incluso la vida de sus hijos y de menores en general puedan casarse y tener hijos (Nussbaum, 2010). La afectividad y el cuidado, como criterio de elegibilidad para el matrimonio, no

\footnotetext{
${ }^{19}$ En algunos casos, se arguye que el daño al niño puede provenir no tanto del medio familiar como del medio social discriminador hacia la homosexualidad que debe enfrentar el niño criado por una pareja homosexual. Siendo esto cierto en muchos casos, ese argumento no tiene cabida, simplemente pues a lo que debe conducir es a políticas orientadas resueltamente a terminar con dicha discriminación social. Si, como lo vemos arriba, los detractores del RJMPMS están en contra de dicha discriminación, deberían hacerse parte de estas políticas en lugar de usarlas como pretexto.
}

126 | AlPHA № 52 (JuLIO 2021) PÁGS. 111-131. ISSN 07 16-4254 
solo juega aquí un rol secundario respecto de la diferencia sexual y la procreación, sino que es directamente olvidada. Es admisible agregar que el mismo argumento opositor critica a parejas homosexuales como queriendo tener interés más en la asimilación a parejas heterosexuales que en una equivalencia jurídica con estas. ¿No se extiende esa asimilación al modo de ejercicio afectivo de los roles parentales? Se aclara además que también hay consenso respecto de que la homoparentalidad no prejuicia necesariamente la orientación sexual de los hijos. En todo caso, incluso si así fuese, eso se podría asumir como daño solo si anteriormente se asume que la homosexualidad es algo negativo, prejuicio del que el argumento opositor dice estar libre. Muy posiblemente familias homoparentales constituyen un medio de crianza en el que los hijos se educan con menos prejuicios y estereotipos (Stacey y Biblarz, 2001).

Los tres puntos críticos mencionados arriba ponen en cuestión la razonabilidad del núcleo del argumento más robusto de los opositores al RJMPMS, y con ello gran parte si no todos sus ramales de justificación. Es meridianamente claro que ese argumento no puede ser aceptado por el legislador o el juez, pues resulta imposible establecer que la discriminación que instaura no sea arbitraria. Más allá de las apelaciones puntuales que realizan los opositores a los argumentos recién dados, hay, en el debate público, un momento en que se abdica de toda racionalidad comunicativa, y se recurre más bien a una conducta estratégica en relación con el uso de la evidencia empírica. Se insiste, por ejemplo, en rebuscar estudios que mostrarían la existencia del mencionado daño. Detrás de esto hay algo más que un mero intento de refutación del consenso que afirma lo contrario: se quiere sustentar algo menor en validez, pero mayor en sus consecuencias; a saber, una duda. Anclada en esta, se afirma ahora que, a causa de la relativa incertidumbre, el Estado debiese abstenerse frente a estas materias, pues sería moralmente inaceptable "experimentar" con la salud psíquica de los niños.

Si es cierto que la variante instrumental de la justificación opositora al RJMPMS es una de las alternativas, la más robusta en todo caso, para darle contenido a aquella estructura elemental basada en la distinción entre matrimonio esencial y jurídico, así como en la exigencia normativa de su coincidencia, entonces sus tesis en realidad no están a disposición de ninguna validación empírica. Según ello, las afirmaciones acerca de la relación entre diferencia sexual, matrimonio, procreación y crianza, en las que se levanta la normatividad de este discurso opositor, no tienen la forma de tesis fuertes disponibles para su contrastación, sino más bien la de principios o decálogos: mujer y hombre se complementan como madre y padre en tanto que el único medio adecuado para la procreación y la crianza. El padre está ontológicamente asociado al hombre y la madre a la mujer. Padre/madre no son roles sociales que pudiesen ser cumplidos por una combinación distinta a la de hombre/mujer, so pena de romper la complementariedad y con ello de generar un medio perjudicial para el niño (Novak, 2010). Lo que no responda a esto es patológico en sí. Es esta fórmula ontológica la que el Estado debiese 


\section{Mauro Basaure}

simplemente sancionar como matrimonio institucional. Este es el núcleo del argumento: una petición de principios, inmune a la evidencia.

El que el uso de evidencia empírica responda muchas veces a un recurso estratégico se pone de manifiesto en los propios debates públicos. En algunos contextos, en una clara contradicción performativa, se rebuscan resultados científicos a favor de dicho argumento y, sin embargo, en el mismo acto, se desprestigia a las ciencias ya sea de modo general atacando su neutralidad (recurriendo al constructivismo, la sociología de la ciencia o a la deconstrucción), o ciertos resultados y fuentes, identificando problemas de método, de transparencia o sesgos de distinto tipo, o incluso denunciando los consensos científicos aludiendo a que estos se logran mediante lobby.

En otros contextos se rechaza tajantemente los resultados de las ciencias empíricas, ya sea porque la cuestión sería de principios, o por que ella debe tratarse como un problema de hegemonía política. En el primer caso, se asume, por ejemplo, que su argumento opositor no depende de los resultados de la investigación científica ${ }^{20} \mathrm{y}$, arguyendo eso, se compara el RJMPMS con una hipotética aceptación legal de relaciones incestuosas: estas deben ser prohibidas independientemente de sus resultados o consecuencias pues confunde generaciones y roles. No es la idea discutir aquí este punto, salvo decir que la comparación no es adecuada pues el RJMPMS no supone ni esa confusión ni ninguna otra, salvo que se acepte la fórmula esencialista que une ontológicamente género a roles.

En el segundo caso, haciéndose eco de la crítica a la ciencia y la técnica, se dice que mediante resultados científicos o el recurso a la lógica de derechos, se busca tratar cuestiones que, finalmente, son de orden político pues pertenecen al ámbito de la decisión y la hegemonía. Esta defensa de la política frente a la ciencia y el derecho, recordemos, se realiza al mismo tiempo que se tiene como trasfondo un argumento esencialista estructurado ontológicamente.

Lo anterior muestra las múltiples estrategias a las que se recurre en el espacio público, según las que las ciencias empíricas son utilizadas según convenga. Nos guste o

\footnotetext{
${ }^{20}$ En otro contexto, Richard Dawkins lo ha planteado irónicamente: “ . . . imagine que, por un conjunto notable de circunstancias, los arqueólogos forenses desenterraran pruebas de ADN para demostrar que Jesús realmente carecía de un padre biológico. ¿Puede imaginar a los apologistas religiosos encogiéndose de hombros y diciendo algo remotamente parecido a lo siguiente? ¿A quién le importa? [...] A nosotros nos preocupan solo las preguntas fundamentales y los valores morales. Ni el ADN ni ninguna otra evidencia científica tiene relación con este asunto" (Dawkins, 2006, p. 59) De hecho, ha sido Hobbes uno de los que ha planteado con mayor claridad un argumento de este tipo. Con su ciencia, él habría descubierto las reglas eternas para hacer y mantener los Estados y la paz. No seguirlas condena a sufrir la miseria que procede de tal ignorancia. Pero su modelo de ciencia no era el de las ciencias basadas en la experiencia o empíricas -a las que desechaba o minusvaloraba-, sino la geometría y la aritmética (Basaure, 2013). Tal como es difícil seguir a Hobbes en esto, así de difícil es aceptar el argumento conservador.
}

128 | AlPHA No 52 (JuLIO 2021) PÁGS. 111-131. ISSN 07 16-4254 
no, frente a estas controversias, no contamos con otro patrón de racionalidad que las conclusiones de las ciencias empíricas, cuando ellas expresan amplios consensos (Rawls 1993), como es aquí el caso. Democracia no significa aquí ni imposición de mayorías ni mera deliberación, sino que deliberación forense ${ }^{21}$.

Como ha quedado demostrado, pese a los esfuerzos justificativos de sus detractores, la discriminación entre parejas heterosexuales y homosexuales respecto de la institución matrimonial es final e inapelablemente arbitraria. El argumento más robusto que puede darse en contra de ello es improcedente, presenta contradicciones insalvables, las que también se expresan en el carácter estratégico de participación en el discurso público. Esa discriminación parece estar condenada a acompañar prontamente a la doctrina separate but equal.

Artículo desarrollado en el marco del Proyecto Fondecyt Regular 1191490, Proyecto Fondecyt Regular 12000493, Proyecto ANID/FONDAP 15130009.

\section{OBRAS CITADAS}

Agacinski, Sylviane (2001). Politique des sexes. Paris: Seuil.

Basaure, Mauro (2015a). On the Critical Turn of Boltanski's Sociology, Iride. Filosofia e discussione pubblica (il Mulino), XXVIII, 75: 403-430.

_ (2015b). Una gramática elemental de la controversia sobre el matrimonio entre personas del mismo sexo. En Figueroa M. (ed.), Liberalismo político. Problemas y desarrollos contemporáneos, Santiago: RIL Editores, 161-178.

_ (2013). From the History of the Peloponnesian War to Leviathan. Hobbes and the Knowledge and Wisdom for Peace", The New Centennial Review, 13(1): 71-91.

__ (2011) Foucault y el Psicoanálisis. Gramática de un malentendido. Santiago: Cuarto Propio.

_ (2002a). Demostrar que no hay sino un mundo. Igualdad y política en Jacques Rancière. Cuadernos Sociológicos 1 (1), 279-312.

— (2002b). Igualdad por Equivalencia. La Estructura Conceptual de la Esfera Pública en Hannah Arendt, Némesis, 2: 103-119.

Basaure, Mauro y Manfred Svensson (eds.) (2015). Matrimonio en conflicto Visiones rivales sobre elmatrimonio entre personas del mismo sexo, Santiago: Cuarto propio.

\footnotetext{
${ }^{21}$ El concepto forense en su sentido original une aquí democracia y ciencia empírica: es el discurso a base de pruebas y testimonios realizado en el foro público.
} 
Benjamin, Walter (2010). Über den Begriff der Geschichte Werke und Nachlass. Kritische Gesamtausgabe. Band 19 Cover: Über den Begriff der Geschichte. Berlin: Suhrkamp Verlag.

Boltanski, Luc (2009). De la critique: Précis de sociologie de l'émancipation, Paris: Gallimard. Brinig, Margaret (2010). Family, Law, and Community. Supporting the Covenant. Chicago: University of Chicago Press.

Browning, Don (2008). Family Law and Christian Jurisprudence. En Witte, J. y Alexander, F. (Eds.), Christianity and Law. An Introduction. Cambridge, Cambridge University Press.

— (2003). Marriage and Modernization. Grand Rapids: Eerdmans.

Browning, Don y Marquardt, Elizabeth (2006). "What About the Children? Liberal Cautions on Same-Sex Marriage". En George, R. y Bethke, J. (Eds.), The Meaning of Marriage. Family, State, Market, \& Morals. Dallas: Spence Publishing Company.

Corvino, John y Gallagher, Maggie (2012). Debating Same-Sex Marriage. Oxford y New York: Oxford University Press.

Dawkins, Richard (2006). The God Delusion. London: Bantam Press.

Derrida, Jacques (2004). Je suis en guerre contre moi-même, Le Monde, 18.08.04, $13 \mathrm{~h} 03$. Eisenstein, Zillah (2009). The Audacity of races and Genders: A personal and global story of the Obama election, London: Zed Books.

Farrow, Douglas (2007). Nation of bastards. Essays on the end of marriage. Toronto: BPS Books.

Finnis, John (1997). Law, morality, and sexual orientation. En Corvino, J (Ed.), Same Sex: Debating the Ethics, Science, and Culture of Homosexuality. New York y London: Rowman and Littlefield.

(1996). Is Natural Law Theory Compatible with limited Government. En George, R. (Ed), Natural Law, Liberalism, and Morality: Contemporary Essays. New York: Oxford University Press.

George, Robert (2006). What's Sex Got to Do with IT? Marriage, Morality, and Rationality. En George, R. y Elshtain. J. (Eds.). The Meaning of Marriage. Family, State, Market \& Morals. Dallas: Spence Publishing Company.

Glendon, Mary Ann (1991). Rights Talk. The Impoverishment of Political Discourse. New York: The Free Press.

Green, Adam Isaiah (2006). Until Death Do Us Part? The Impact of Differential Access to Marriage on a Sample of Urban Men, Sociological Perspectives 49 (2): 163-189.

Guzmán, Alejandro (2005). La influencia del Código Civil francés en las codificaciones americanas. Cuadernos de Análisis Jurídico, II, 1, 27-60.

Kirkpatrick, Rob (2000). The Evolution of Human Homosexual Behavior, Current Anthropology 41 (3): 385-413. 
Luhmann, Niklas (1994). Liebe als Passion. Frankfurt/M.: Suhrkamp. (1969). Legitimation durch Verfahren. Frankfurt/M.: Suhrkamp.

Mascareño, Aldo (2015). Matrimonio entre personas del mismo sexo y la selección evolutiva de la conducta homosexual. En Basaure, M. y Svensson, M. (Eds.), Matrimonio en conflicto Visiones rivales sobre el matrimonio entre personas del mismo sexo, Santiago: Cuarto propio.

Massini-Correas, Carlos (2014). Sobre bienes humanos, naturaleza humana y ley natural. Reflexiones a partir de las ideas de Javier Hervada y John Finnis, Persona y Derecho, 71 (2): 229-256.

Muscarella, Frank (2000). The Evolution of Homoerotic Behavior in Humans, Journal of Homosexuality 40 (1): 51-77.

Novak, David (2010). Response to Martha Nussbaum's ‘A Right to Marry?', California Law Review, 98 (3): 709-720.

Nussbaum, Martha (2010). A right to marry?, California Law Review 98 (3): 667-696.

Oeser, Erhard (2004). Evolution and Constitution: The Evolutionary Selfconstruction of Law, Dordrecht: Kluwer Academic Publisher.

Rancière, Jacques (2004). Aux bords du politique. Paris: Gallimard.

Rawls, John (1993). Political Liberalism. New York: Columbia University Press.

Rimmerman, Craig y Clyde Wilcox (Eds.). (2007). The Politics of Same Sex Marriage. Chicago: The University of Chicago Press.

Schneider, Michel (2005). Big Mother. Psychopathologie de la vie politique. Paris: Odile Jacob.

Stacey, Judith y Timothy Biblarz (2001). "(How) does the sexual orientation of parents matter?”. American Sociological Review, 66 (2):159-183.

Stemmer, Peter (2008). Normativität. Eine ontologische Untersuchung. Berlin: DeGruyter.

Sullivan, Andrew (1997). Same-Sex marriage: Pro and Con. New York: Vintage books. Tapia, Mauricio (2005). Código Civil 1855-2005. Evolución y perspectivas. Santiago: Editorial Jurídica de Chile.

Thaler, Richard y Sunstein, Cass (2008). Nudge. Improving decisions about health, wealth, and happiness. New Haven: Yale University Press.

Wardle, Lynn et al. (eds.) (2003) Marriage and Same-Sex unions: A Debate. Westport, CT: Greenwood.

Weber, Max (1995).Die Objektivität sozialwissenschaftlicher und sozialpolitischer Erkenntnis. Tübingen: J.C.B. Mohr.

Witte, J. y Nichols, J. (2008). "More than a Mere Contract: Marriage as Contract and Covenant in Law and Theology”. University of St. Thomas Law Journal 5:2: 595-615. 